\title{
Plan de manejo silvicultural para la recuperación de los bosques tropicales húmedos en la zona afectada por el huracán Félix
}

\author{
Holmes Antonio Aguilar Flores \\ Universidad Nacional de Ingeniería (UNI)
}

Nicaragua tiene una extensión superficial de 120,339.54 kilómetros cuadrados de tierras emergentes y una cubierta forestal de $57,372.21 \mathrm{~km}^{2}$ de bosques, para una cobertura porcentual del $47.66 \%$. De la totalidad de bosques actuales, $32,948.73 \mathrm{~km}^{2}$ son bosques cerrados, considerando pinares y latifoliados, lo que se puede considerar como el área efectiva actual de bosques cerrados (27.38\% del país). (FAO, 2000).

Los bosques latifoliados húmedos de Nicaragua antes del dos de septiembre del año 2007 se estimaban en 31,773.76 km² $^{2} 3,177,376$ ha), Según el Dr. Juan Bautista Salas, casi todas las tierras de la región ecológica 4 sector atlántico del país, están dentro de un clima subtropical, todos los bosques latifoliados son de tipo perennifolio, la mayor parte de las especies vegetales se desplazan en toda la región en una extensión de tierra de 52,000 km², que abarca el $83 \%$ de las tierras de la región ecológica.

La evaluación también reflejó que en el tema de cambio climático se obtuvo un volumen equivalente a 65,9 millones de metros cúbicos de biomasa tumbada, lo que ocasionó un incremento de las emisiones de dióxido de carbono (CO2) de aproximadamente $74 \%$. La mortalidad y migración de mamíferos, aves, reptiles a otros ecosistemas, es otro resultado del paso del huracán, ya que la ausencia de semillas, insectos y frutas para su alimentación son factores trascendentes para la sobre vivencia de estos mamíferos.

Enormes cantidades de sedimentos arrastrados por el río Coco y otros ríos redujeron la disponibilidad de pasto marino, principal alimento de la tortuga verde, también dañaron los arrecifes de coral, ubicados al norte de los Cayos Miskitos y esto disminuiría las poblaciones de langostas. La destrucción del bosque de mangle disminuirá sensiblemente la población de ostras, conchas y otras especies. (MARENA, septiembre 2007)
Se estiman los daños ambientales en 599 millones de dólares, utilizando valoraciones económicas ambientales valorados en países centroamericanos y se aplicaron al total de hectáreas de daño severo y severo a grave. Los daños se midieron en la pérdida de captura de $\mathrm{CO} 2$, protección de aguas, biodiversidad y protección de los ecosistemas. (INAFOR, septiembre, 2007).

\section{PROBLEMA}

Daños en la biodiversidad y estructura de los bosques tropicales húmedos causados por los efectos del Huracán Félix en la Región Autónoma del Atlántico Norte de Nicaragua (RAAN).

\section{HIPOTESIS}

Si se determinan a través de mediciones dasométricas el comportamiento dinámico de la regeneración natural de los bosques tropicales húmedos afectados por el huracán Félix, con el empleo de modelos que reflejen las transformaciones de estructura y composición de especies arbóreas, entonces se podrá diseñar un plan de manejo silvicultural que permita la recuperación de la biodiversidad de especies forestales en la zona.

\section{OBJETO DE ESTUDIO:}

Los bosques tropicales húmedos afectados por el huracán Félix

\section{CAMPOS DE ACCIÓN:}

Plan de manejo silvicultural en Bosques Tropicales Húmedos con mediciones dasométricas en las parcelas de muestreo, la distribución espacial horizontal y vertical de las especies predominantes, así como los tratamientos 
silvícola que puedan inducir la recuperación de la biodiversidad forestal.

\section{OBJETIVOS:}

\section{Objetivo general:}

Diseñar un plan de manejo silvicultural para la recuperación de los bosques tropicales húmedos en la zona afectada por el huracán Félix en la Región Autónoma del Atlántico Norte de Nicaragua.

\section{Objetivos específicos:}

1. Caracterizar el estado actual de los bosques tropicales húmedos en la RAAN de Nicaragua.

2. Diagnosticar la situación ambiental de las comunidades indígenas miskitas y mayangnas que indiquen las acciones positivas y negativas de éstas sobre los bosques tropicales húmedos.

3. Diseñar un plan de manejo para el ordenamiento y manejo silvícola de los ecosistemas forestales afectados por el paso del huracán Félix en los bosques tropicales húmedos de la RAAN.

\section{RESULTADOS ESPERADOS}

1) Una Caracterización del comportamiento dinámico de los bosques tropicales húmedos en la Región Autónoma del Atlántico Norte de Nicaragua, dentro de la zona de mayor impacto del huracán Félix.

2) El comportamiento social, ambiental y económico de las comunidades indígenas miskitas y mayangnas que indiquen las acciones positivas y negativas de éstas sobre los bosques tropicales húmedos dañados en las zonas de daños altos del huracán Félix.

3) Un modelo matemático que muestre la recuperación de la biodiversidad de especies forestales en los bosques tropicales húmedos afectados por fenómenos naturales.

4) Presentación de un manejo silvícola de los ecosistemas forestales afectados por el paso del huracán Félix en los bosques tropicales húmedos de la RAAN.

\section{METODOLOGIA DE LA INVESTIGACION}

\section{Parcelas de Muestreos Permanentes (PMP)}

Estas son de forma rectangular, con un ancho de $20 \mathrm{~m}$ (10 m a cada lado de la "pica"), y una longitud de $500 \mathrm{~m}$, abarcando una extensión de 1 ha cada parcela. Esta se subdivide en 10 subparcelas de $100 \times 10 \mathrm{~m}$, numeradas de 1 a 10; y dentro de ellas se establecen 5 parcelas pequeñas de 4 x 10 en las subparcelas $(1,4,5,8$ y 9) para el registro de regeneración de brinzales y latizales. Los fustales se medirán solamente en las sub parcelas 1, 4, 5, 8 y 10 en parcelas de tamaño de 10 x 20. Los estratos se dividen en Fustales ( $\geq 10 \mathrm{~cm} \mathrm{y}<25 \mathrm{~cm}$ dap) y en todas se medirán los arboles $\geq 25 \mathrm{~cm}$. Dap. Subparcelas de 10 x 20, donde se medirán los latizales ( $\geq 5$ cm y $<10$ cm dap) y esta se dividirá en 5 Sub-parcelas de $10 \times 4$ para definir donde en la número 1 se medirá la regeneración natural a nivel de brinzales $(30 \mathrm{~cm}$ de altura y $<5 \mathrm{~cm}$ dap).

\section{MEDICION DE ÁRBOLES}

Identificación de la especie

Diámetro

Calidad de fuste (1-6)

Altura Comercial

\section{MUESTREO DE LA REGENERACION}

Brinzales (30 cm de altura y $<5 \mathrm{~cm}$ dap)

Latizales ( $\geq 5 \mathrm{~cm} \mathrm{y}<10 \mathrm{~cm}$ dap)

Fustales ( $\geq 10 \mathrm{~cm} \mathrm{y}<25 \mathrm{~cm}$ dap)

\section{RESULTADOS}

Resultaron 137 especies de mucha importancia para la biodiversidad de las especies existentes en los bosques, de las cuales 76 tienen una importancia para la alimentación, anidamientos de aves, alimento de mamíferos y de uso doméstico para los comunitarios de esta zona, y 61 especies tienen valor en uso medicinal, consumo doméstico y valor cultural.

Por la complejidad de los nombres comunes de las especies se está trabajando para realizar un manual de reconocedor con fotografías de las especies para poder ubicarlas taxonómicamente, trabajo que resultará en el periodo de investigación del año 2009 e inicio del 2010. 
Un total de 18 especies de alto valor comercial dividiendo este grupo en tres grupos: a) Dominantes, b) Critico, c) Peligro de extinción, Para realizar el análisis de dominancia según su distribución espacial, dentro del grupo Dominante o de mayor frecuencia se encuentran seis especies predominando la Synphonia globulifera a nivel de latizal, superando a la especie de Vochysia ferruginea luego que ésta aparece como dominante a nivel de brinzales llegando estas dos especies a dominar en un $49 \%$ su frecuencia a nivel de regeneración natural. Luego tenemos tres especies muy conocidas en el mercado internacional el Andiroba Carapa o Cedro macho guianensis quien mantiene una buena distribución espacial con un 14\% y el Framire o Guayabo negro Terminalia sp. Que a comparación con la Tetragastris panamensis demuestra un alto nivel de competencia.

El comportamiento social, ambiental y económico de las comunidades indígenas miskitas y mayangnas que indiquen las acciones positivas y negativas de estas sobre los bosques tropicales húmedos dañados en las zonas de daños altos del huracán Félix.

Las instituciones del estado realizaron un análisis de las acciones y sus costos para los próximos años partiendo de 1)- Regular y controlar el acceso al recurso forestal afectado en la Reserva de Biosfera BOSAWAS 678,000 dólares. 2)Implementar la restauración de los ecosistemas de bosques afectados 300,000 dólares, 3)- Regular y controlar el acceso al recurso forestal afectado en los municipios de Waspan, Puerto Cabezas y Prinzapolka 32,253 dólares. 4)-Acompañar las acciones de restauración ambiental en la zona marino costero de la RAAN, 26,600 dólares. 5).Prevenir y controlar los incendios forestales y quemas agrícolas en Bosawás 77,400 dólares, para un total general de 1,113,253 Dólares. Ningunas de estas acciones se han podido realizar por falta de presupuesto y aun si así fuese no sería lo suficiente.

\section{CONCLUSIONES}

- Relevar los mecanismos de recuperación asociados con el nivel de daño (Alto, Medio solamente), para entender cómo el bosque se recupera y así determinar la mejor forma de utilizar sus recursos. Todo mediante las mediciones sistemáticas de las parcelas de muestreos permanentes tanto en zonas sin intervención maderera, en zonas con intervención maderera, zonas de reforestación como práctica silvícola.

Realizar estudios sistemáticos de investigación con mediciones cada seis meses durante los próximos 12 meses sobre la dinámica del bosque tanto horizontal como vertical en diferentes niveles de disturbio (alto, medio y bajo).

Analizar económicamente cual de los mecanismos de recuperación de la regeneración es más económico, medible y fácil de establecer, que ayuden a liberar a las especies ecológica y económicamente más importantes para plantear alternativas de manejo a largo plazo. Tal como la remoción de la regeneración natural en su distribución espacial a través del Sistema de Raíz desnuda de la Regeneración Natural en vez de establecer viveros que son más costosos y dejan pocos beneficios a las comunidades. En cambio es mejor invertir en mano de obra de brigadas de remoción a raíz desnuda que producir plántulas en viveros y en transporte de éstas en las incomodidades que se encuentra la montaña.

- Establecer recolección de semillas para bancos de reproducción en sitios internos de la montaña garantizando la producción de plantas de doble propósito AVC y AVE, que tienen un alto valor para la conservación, como las especies Swietenia macrophylla (NC. Caoba), Hymenaea courbaril (NC. Guapinol, NCo. Jatoba), Virola multitlora, (NC. Banak, NCo. Sebo)Terminalia amazonia (NC. Guayabo), Terminalia oblonga (NC. Guayabo Negro), Hyeronima alchorneoides Allem (NC. Nanciton), Manirasa sp. (NC. Zapote de mico).

Mediante los resultados de los Diagnósticos Comunitarios forestales, proponer las posibilidades de aplicar a pagos por servicios ambientales o mecanismos de fideicomisos con empresas de inversión forestales. 